\title{
Clinical Utility and Cost Effectiveness of Complement 3 and Complement 4 in Different Clinical Subspecialties in Hamad Medical Corporation
}

Graduate students, Population, Health \&Wellness
Foziyeh Naji1 ${ }^{1}$ Mohammed Ehlayel ${ }^{2}$, Nader Al-Dewik ${ }^{3}$, Ahmed Malki $^{4}$

${ }^{1}$ Department of Laboratory Medicine and Pathology, Hamad Bin Khalifa Medical City, Hamad Medical Corporation, and College of Health Sciences,

Qatar University.

${ }^{2}$ Ped Allergy-Immunology, Pediatrics Dept., Hamad Medical Corporation and Pediatrics Dept., Weill Cornell Medical College, Doha, Qatar.

${ }^{3}$ Department of Pediatrics, Women's Wellness and Research Center, and Interim Translational Research Institute, Hamad Medical Corporation, and

College of Health and Life Sciences, Hamad Bin Khalifa University, Doha, Qatar.

${ }^{4}$ College of Health Sciences, Qatar University, Doha, Qatar.

\section{BACKROUND}

Complement proteins 3 (C3) and 4 (C4) are key biomarkers of disease activity, commonly done in clinical immunology laboratory at Hamad Medical Corporation (HMC).

\section{INTRODUCTION}

$\mathrm{C} 3$ and $\mathrm{C} 4$ are core plasma proteins activated in numerous diseases including autoimmune diseases[1], sepsis [2], and many others.

Correct medical decisions are based on laboratory results. However, appropriate utilization of $\mathrm{C} 3 / \mathrm{C} 4$ by clinicians is essential in maintaining laboratory and financial resources of HMC.

\section{OBJECTIVES}

- To study the clinical utility of C3 and C4 in different clinical subspecialties in HMC.

- To study the cost effectiveness of C3 and C4 among different clinical subspecialties HMC.

\section{METHODS}

A retrospective study, on electronic medical records of 326 patients tested between $1^{\text {st }}$ January and 31 March 2017 in clinical immunology laboratory at HMC, Doha-Qatar.

The data collected included patient's demographical, disease categories, complement test results and financial cost.

Descriptive statistics (median, mean, range, frequency and percentages), and Chi square analysis were calculated.

\section{RESULTS}

Table 1: Basic demographics data of 326 patients with $\mathrm{C} 3$ and $\mathrm{C} 4$ tests

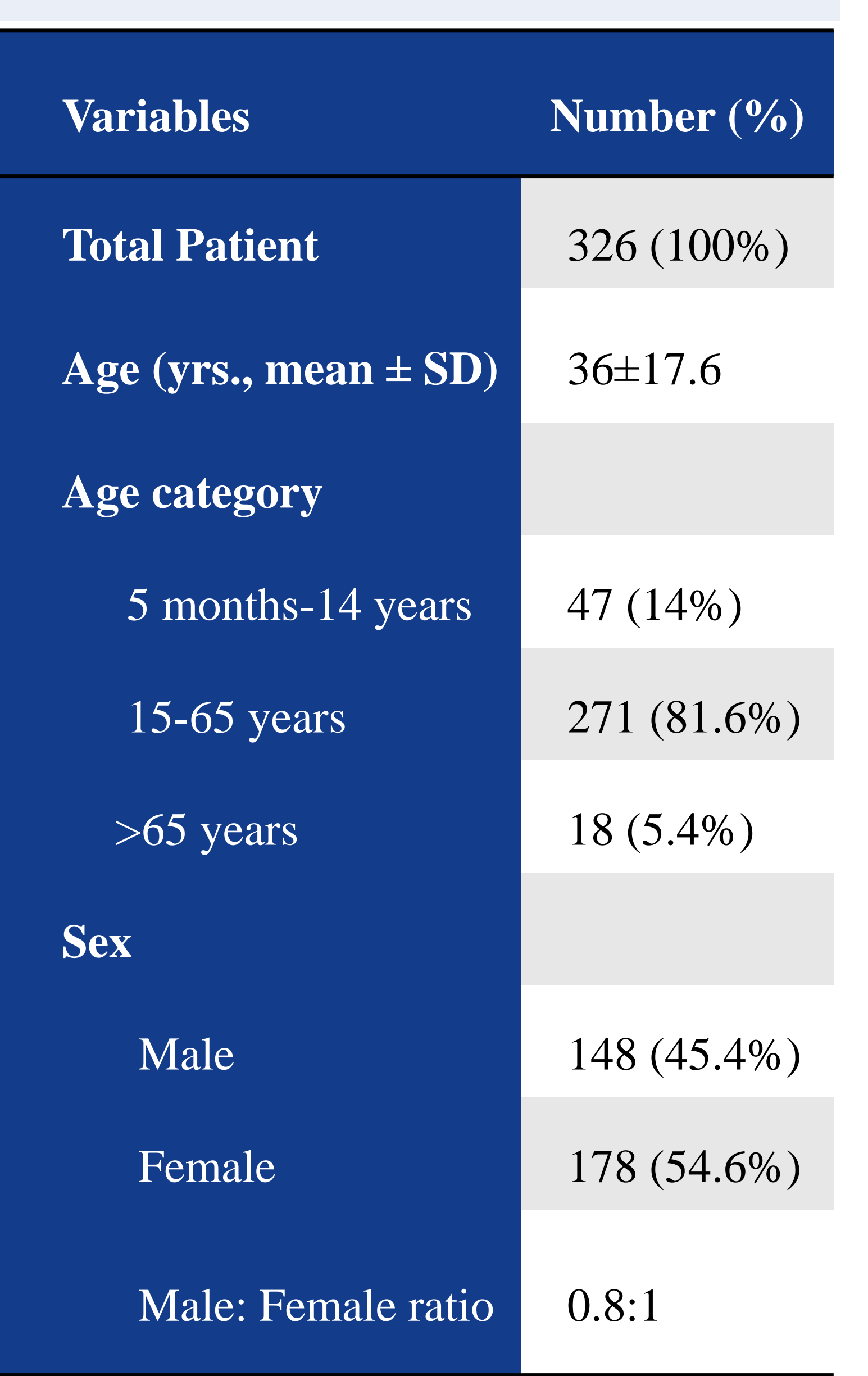

Fig 1: Distribution of patients according to disease type.

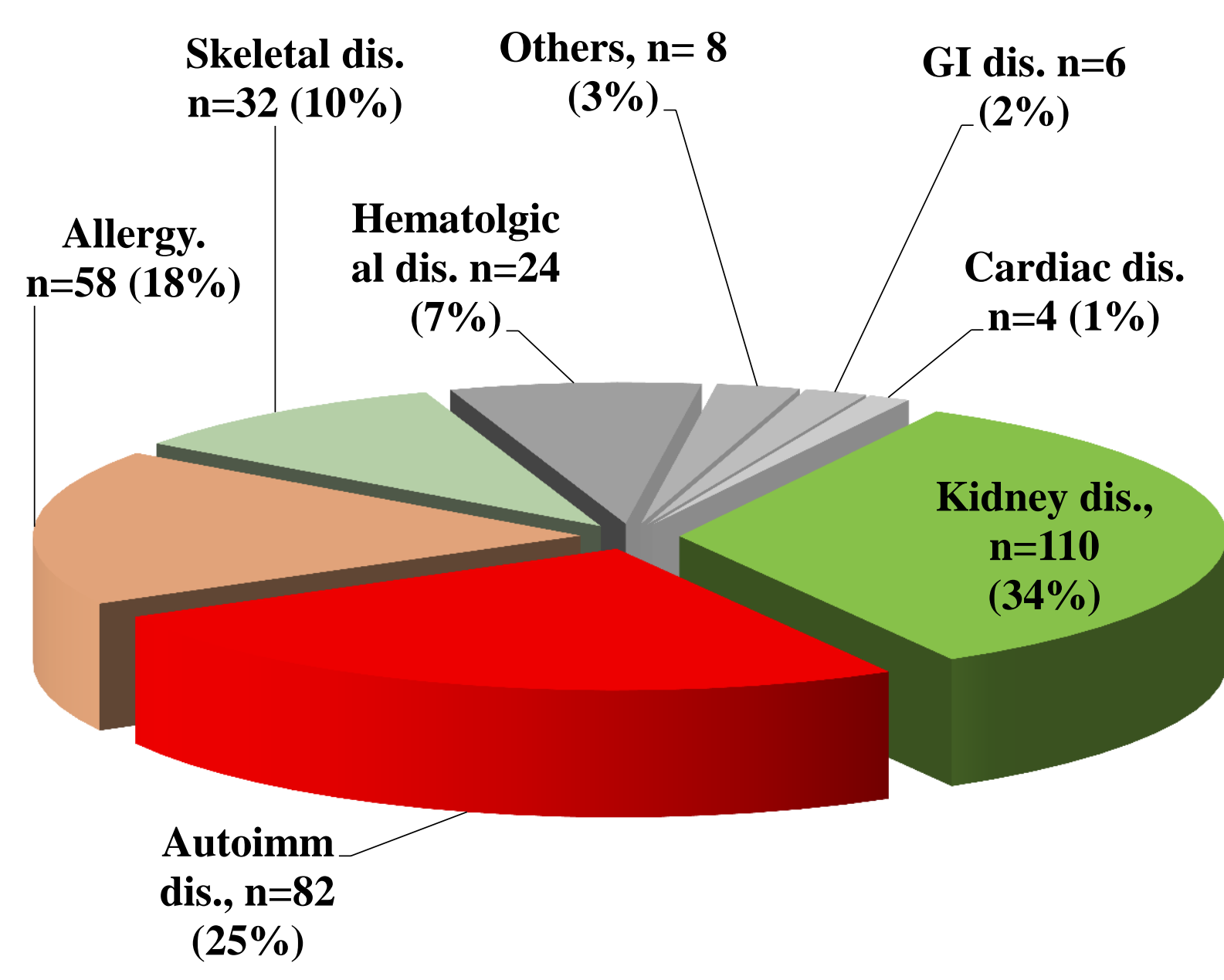

The top 3 diseases constituted $77 \%$ of all diseases where $\mathrm{C} 3$ and $\mathrm{C} 4$ tests were ordered as:

- Kidney diseases: $34 \%$

- Autoimmune diseases: $25 \%$

- Allergic diseases: $18 \%$.
Fig 2: Percentages of $\mathrm{C} 3, \mathrm{C} 4$, and both in patients.

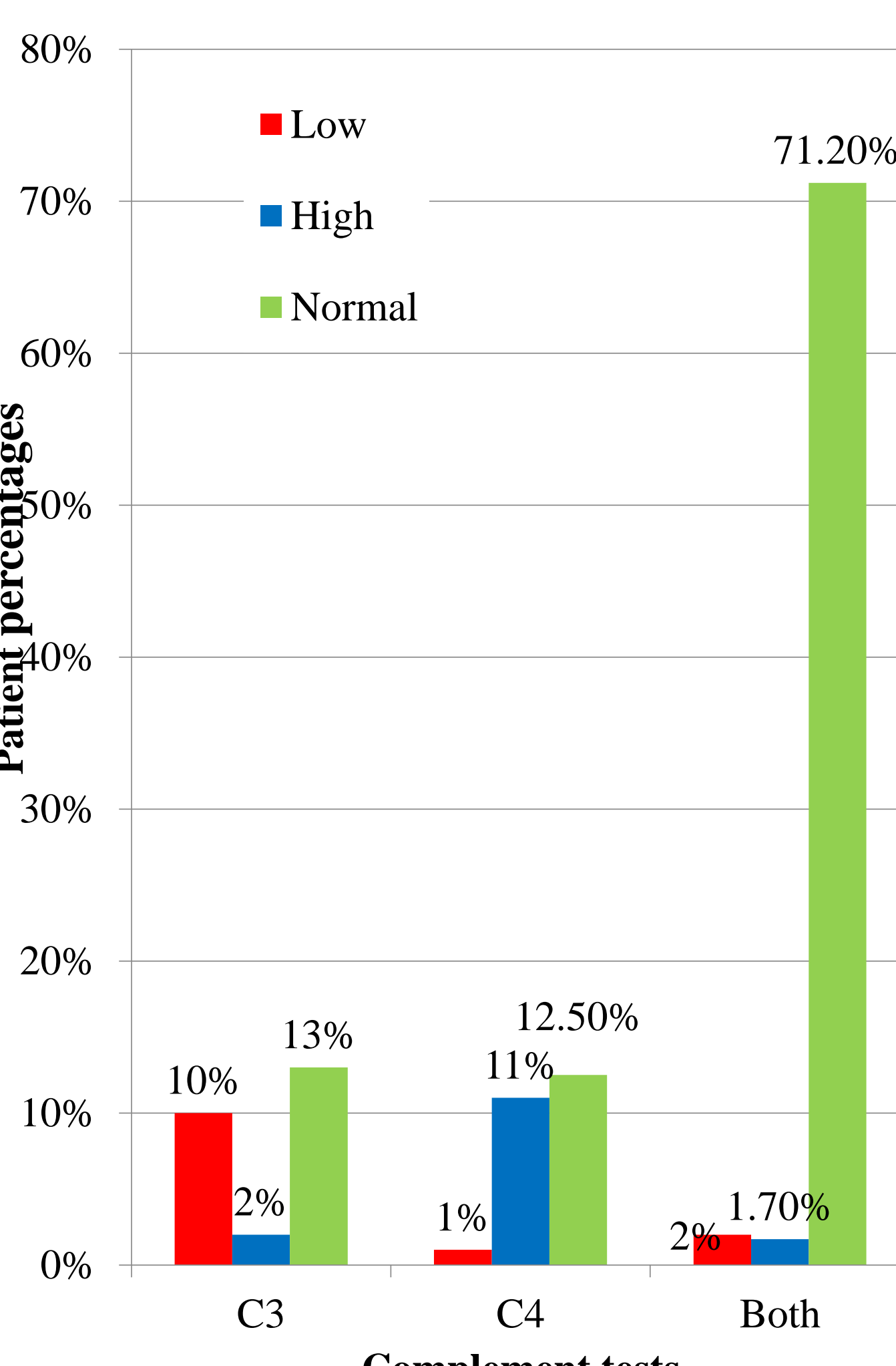

Abnormal C3 and C4: 29\% Low C3/C4: $13 \%$

High C3/C4: 16\%

Table 2: Calculation of $\mathrm{C} 3$ and C4 cost at HMC.

\begin{tabular}{|c|c|c|}
\hline Cost type & Phase & $\begin{array}{c}\text { Mean cost } \\
\text { (QR) }\end{array}$ \\
\hline $\begin{array}{c}\text { Pre- } \\
\text { Direct } \\
\text { Cost } \\
\text { phalytical }\end{array}$ & $\begin{array}{c}\text { Analytical } \\
\text { phase** }\end{array}$ & 12.12 \\
\hline $\begin{array}{c}\text { Indirect } \\
\text { Cost }\end{array}$ & & 3.65 \\
\hline Total & & 21.93 \\
\hline
\end{tabular}

Table 3: Cost of C3, C4, or both in private healthcare providers across Qatar

\begin{tabular}{|c|c|c|c|}
\hline Private HC & \multicolumn{3}{|c|}{ Cost (QR) } \\
\cline { 3 - 5 } Providers & C3 & C4 & Both \\
\hline Hospital 1 & 150 & 150 & 300 \\
\hline Hospital 2 & 150 & 150 & 300 \\
\hline Lab 1 & 300 & 300 & 600 \\
\hline Lab 2 & 190 & 190 & 380 \\
\hline Average & 197.5 & 197.5 & 395 \\
\hline SD & $\begin{array}{c}70.88 \\
723\end{array}$ & $\begin{array}{c}70.88 \\
723\end{array}$ & $\begin{array}{c}141.7 \\
745\end{array}$ \\
\hline
\end{tabular}

CONCLUSIONS

This is the first study of its kind to address the clinical utility and cost effectiveness of $\mathrm{C} 3$ and $\mathrm{C} 4$ test at HMCQatar. Although the cost of a single test of $\mathrm{C} 3$ or $\mathrm{C} 4$ is low, the total annual cost is huge. The treating physician is recommended to exercise judicious clinical wisdom when ordering $\mathrm{C} 3$ or $\mathrm{C} 4$ tests as diagnostic tools.

\section{REFERENCES}

1. Thurman and Yapa R. Front Immunol. 2019;10:672.

2. Karasu E, et al. Front Immunol. 2019;10:543.

ACKNOWLEDGEMENT

- No conflicts of interest related to this research.

- It was approved by IRB at HMC, Protocol, No: MRC-01-19-089. 